\title{
Contraception and family planning among HIV-seroconcordant and -serodiscordant couples in the US and Zambia
}

This article was published in the following Dove Press journal:

Open Access Journal of Contraception

7 May 2010

Number of times this article has been viewed

\section{Deborah L Jones' \\ Olga Villar-Loubet' \\ Chipepo Kankasa ${ }^{2}$ \\ Ndashi Chitalu ${ }^{2}$ \\ Miriam Mumbi² \\ Stephen MWeiss'}

'Department of Psychiatry and Behavioral Sciences, University of Miami Miller School of Medicine, Miami, FL, USA; '2Department of Paediatrics, University of Zambia School of Medicine, Lusaka, Zambia

Correspondence: Deborah L Jones Department of Psychiatry and Behavioral Sciences, University of Miami Miller School of Medicine, 1400 NW 10th Ave, Miami, FL 33 I 36, USA

Tel +I 3052432103

Fax +I 3052432126

Email djones@med.miami.edu
Abstract: With the advent of antiretroviral therapy, remarkable progress has been made in the reduction of morbidity and mortality associated with the human immunodeficiency virus (HIV). As a result, in both the developed and developing world, reproductive decision-making and family planning has re-emerged as an important health issue among HIV-seroconcordant and -serodiscordant couples. This study sought to explore contraceptive attitudes and practices among HIV-seropositive and -serodiscordant couples in the US and Zambia and to compare contraceptive decision-making between seroconcordant and discordant couples. Study results suggest that while most participants expressed a willingness to use protection to prevent pregnancy, the majority were not using protection consistently. Similarly, among seropositive younger men in both the US and Zambia, more men expressed a desire to have children than women of either serostatus group. Study outcomes also suggest that male and female condom use to reduce HIV transmission within couples is limited. Thus, as males are largely the sexual decision makers regarding condom use, women's attitudes or plans regarding child bearing may be eclipsed by those of their male partners, and recent reductions in provision of female condoms in the developing world may further reduce women's options to protect themselves and prevent pregnancy. Education and counseling on vertical and horizontal transmission of HIV among both seropositive and serodiscordant couples should be an element of family planning efforts. Conversely, family planning should be a critical element of HIV counseling and testing strategies to realistically respond to the desires of both members of the couple.

Keywords: urban, decision-making, condom use, HIV transmission

\section{Introduction}

With the advent of antiretroviral therapy, remarkable progress has been made in the reduction of morbidity and mortality associated with the human immunodeficiency virus (HIV). As a result, in both the developed and developing world, reproductive-decision making and family planning has re-emerged as an important health consideration among HIV-seroconcordant and -serodiscordant couples. The rate of contraceptive use is lower in sub-Saharan Africa (22\%) than developed regions of the world $(62 \%)^{1}$ and the need for modern contraceptive methods appears to exceed their actual use. ${ }^{2}$ Modern contraceptive methods here refer to female and male sterilization, intrauterine devices (IUDs), hormonal methods (eg, oral pills, injections, hormone implants, skin patches, vaginal rings), condoms and vaginal barriers (eg, diaphragms, cervical caps and spermicides). Traditional contraceptive methods referring to abstinence, withdrawal, the rhythm methods and lactational amenorrhea. $^{3}$ 
Zambia has a population of 12 million people, of whom an estimated 1.1 million are living with HIV. It has been particularly hard-hit by the HIV/acquired immune deficiency syndrome (AIDS) pandemic, with infection rates as high as $42 \%$ among pregnant women in Lusaka, the capital city (Brian Chituwo, Minister of Health, personal communication, 2008). Urban antenatal clinics in regions such as Livingstone have reported rates as high as $32.3 \% .{ }^{4}$ Nationwide, the HIV prevalence rate among pregnant women is $19.3 \%$ and it is estimated that approximately 95,000 children are currently HIV-positive. ${ }^{5}$ More than $90 \%$ of these infections are the result of mother-to-child transmission (MTCT) of HIV. HIV is predicted to increase infant mortality to 82 per 1,000 live births. ${ }^{6}$

A woman's identity may be embodied by her reproductive and childbearing ability, regardless of her HIV status, culture, or the potential health risks associated with HIV transmission, pregnancy, and giving birth. ${ }^{7}$ In sub-Saharan Africa, a woman's 'purpose in life' includes her ability to bear children and many women report feeling pressured by their community and society to have children. ${ }^{89}$ Social pressure may not differentiate between those who are HIV seropositive and those who are seronegative. Among HIV-positive men and women in Kenya and Malawi, those who were married or cohabitating were more likely to be sexually active and to use condoms less than those who were not married or cohabitating. ${ }^{10}$ Slightly less than half, $44 \%$, of HIV-positive Kenyan women and $40 \%$ of HIV-positive Malawian women reported that their last pregnancy was unplanned or unwanted. Unwanted pregnancy rates in sub-Saharan Africa are estimated to be $20 \%-40 \% .^{10,11}$ A recent study found that only $21 \%$ of women with a sexual partner use modern contraceptive methods, and in another study, less than $25 \%$ of women reported using modern contraceptives. ${ }^{10,11}$ Of HIV-positive women in Kenya and Malawi who reported not ever wanting a child or not within the next 2 years, less than one-third and one-fifth, respectively, were using modern contraceptives. ${ }^{10}$ In addition, health risks associated with pregnancy are high in sub-Saharan Africa. Among women who are HIV seronegative, an estimated one in every 22 women in sub-Saharan Africa has a lifetime risk of dying owing to complications during pregnancy. ${ }^{12}$ Finally, HIV infection rates for women are higher than those for men in Zambia (54\% of all infections are among women) and $85 \%$ of HIV infections in women occur in marital and cohabiting relationships. ${ }^{4,13}$ Thus, among those women wishing to produce children, health risks include those associated with pregnancy, birth, and both horizontal (between sexual partners) as well as vertical transmission (from mother to child), while contraception use appears to be modest.

A study of serodiscordant couples in Rwanda and Zambia found that, in both locations, knowledge of contraception was high, yet actual contraception use was low. ${ }^{14}$ Although contraceptive use is higher for women in Zambia than Rwanda, women in both settings reported greater knowledge and use of contraceptive methods than men, leading the investigators to conclude that women may use contraceptives without their partners' involvement or knowledge. ${ }^{14}$ Of women surveyed in Zambian prenatal clinics in 2004, only $19 \%$ reported they had ever had sex while using a male condom to protect against sexually transmitted diseases (STDs) and/or HIV. ${ }^{4}$ Clearly, many seropositive men and women are prepared to risk HIV transmission and HIV re-infection rather than diminish their reproductive potential ${ }^{8,9,15}$ and the acceptability and use of sexual barrier products are influenced by values related to bearing children.

Not unlike female populations in sub-Saharan Africa, of the estimated 146,692 adolescent and adult females living with HIV/AIDS in the 34 of the United States (US) reporting HIV infection rates, the vast majority are in their reproductive years. ${ }^{16}$ In 2007, $68 \%$ of new HIV infections in the US were among women of childbearing age, with $81 \%$ of these being among minority women. ${ }^{16}$ Estimates from the pre-highly active antiretroviral therapy (HAART) era (1988-1994) suggested that 7,000 HIV-positive women would become pregnant each year. ${ }^{17}$ With the advent of effective therapeutic interventions for HIV-positive mothers, the live birth rate is now $150 \%$ higher than in the pre-HAART era. ${ }^{18} \mathrm{~A}$ review of factors influencing fertility desires and intentions among HIV-positive women in the US found that $30 \%$ of women in Ohio, $55 \%$ in Louisiana, and $40 \%$ from southern states (Georgia, and North and South Carolina) had been pregnant since their diagnosis. ${ }^{19}$ These numbers may be related to a variety of factors, including an increase in prenatal screening, the spread of HIV infection through heterosexual contact, but most likely, the desire of women to bear children despite health concerns. ${ }^{20,21}$

In the US, reproductive decision-making among AfricanAmerican women living with HIV appeared to be influenced by misinformation associated with transmitting the virus to their children. ${ }^{8}$ Other factors associated with decisionmaking included previous reproductive experience (eg, live births, abortions), social support, spiritual and religious beliefs and practices, as well as the woman's own health status. ${ }^{22-27}$ Among HIV-seropositive and -seronegative African-American women, self-esteem and self-efficacy were 
not as strongly predictive of the desire for children as was age, previous reproductive experience (ie, abortions), and religious beliefs. ${ }^{28}$ Finally, many HIV-seropositive AfricanAmerican women plan to have children despite their own uncertainty regarding the potential of MTCT. ${ }^{8}$ While older HIV-positive women expressed relief about not having to make the decision of planning a pregnancy while living with the virus, younger women reported that deciding to become pregnant, or resolving how to respond to an unplanned pregnancy, was not determined by their HIV status. . $^{84,25,27}$

Clearly, there is a need to minimize exposure to HIV and STDs while maximizing the potential to become pregnant, in contrast to the current practice of unrestricted unprotected sex when seeking to become pregnant. ${ }^{29}$ Family planning and contraceptive use among people living with HIV worldwide is a growing priority in research. ${ }^{30}$ Thus, information on the contraceptive methods and plans of couples living with HIV can inform strategies and interventions designed to reduce vertical and horizontal HIV transmission in this population. This study sought to explore contraceptive attitudes and practices among HIV-seropositive and -serodiscordant couples in the US and Zambia and to compare contraceptive decision-making between seroconcordant and discordant couples.

\section{Material and methods}

\section{Participants and recruitment}

This study presents data drawn from a larger ongoing study, the NOW2 Project (R01MH63630).

Prior to participant recruitment, research reviews and approvals were obtained in accordance with the provisions of the US Department of Health and Human Services, the University of Miami Miller School of Medicine (UMMSM) Institutional Review Board (IRB), and the University of Zambia Research Ethics Committee (REC). Participants were recruited between May 2005 and October 2009, were 18 years of age or older, and were sexually active HIV-serodiscordant and -seroconcordant heterosexual couples living in urban Miami, Florida, USA and Lusaka, Zambia. Participants were screened for eligibility, ie, currently sexually active, aged 18 years or older, in a couple relationship (relationship defined here as having existed a minimum of 6 months, to reduce potential attrition due to separation), and at least one member of the couple being HIV seropositive.

Participants at the Miami site ( $n=223$ couples) were recruited from clinic sites at the UMMSM/Jackson Memorial Hospital (JMH) and outlying community health clinics in Miami-Dade County. Lusaka site participants $(n=220$ couples) were recruited from The University Teaching Hospital (UTH) Voluntary Counseling and Testing Family Support Unit (VCT-FSU) and additional participants were recruited from KARA Counseling Centre, the Network for Zambian People Positive (NZP+), and outlying Community Health Clinics in the Lusaka urban area.

Almost all of the individuals approached agreed to participate; approximately 5\% declined. Approximately 27\% of couples screened for enrollment in the US and Zambia did not meet the couple relationship criteria (they had no partner, were not in a relationship for more than 6 months, had undergone a recent break-up); an additional 5\% were ineligible owing to lack of sexual activity within the previous month. In the US, all consents and assessments were conducted in English. In Zambia, all consents and assessments were conducted in English, or Nyanja or Bemba (primary local languages in Lusaka), and all Zambian study staff were fluent in all three languages.

Following provision of informed consent, both couple members completed a baseline assessment of sexual and demographic data using Audio Computer Assisted SelfInterview (ACASI). ${ }^{31}$ Participants received monetary compensation for their time and travel expenses (US: \$60 per assessment; Zambia: K50,000 per assessment). Participants were screened for STDs and HIV at enrollment via urine samples for gonorrhea and chlamydia and blood samples for syphilis and HIV, if HIV status was unknown. HIV-seropositive participants were required to provide verification of serostatus prior to enrollment. Participants were notified of their test results and referred for appropriate no-cost treatment for STDs prior to being enrolled in the study. Those participants newly identified as being HIV seropositive were referred for counseling and assessment for HAART. Owing to distress following an HIV diagnosis, participants testing newly HIV seropositive were not eligible to enroll for 2 weeks post-diagnosis.

\section{Measures \\ Demographics}

This questionnaire included collection of data on age, ethnicity, educational level, employment status, HIV serostatus, approximate date of HIV diagnosis, mode of infection, marital status, current partner's and children's serostatus, family planning, and number of children.

\section{Sexual activities questionnaire}

This 55-item scale was adapted from the Sexual Risk Behavior Assessment Schedule (SERBAS). ${ }^{32}$ Responses 
indicated the frequency of heterosexual sexual intercourse (vaginal, oral, anal) in the past 3 months with primary (most frequent sexual relations) and non-primary partners (any other male partners), sexual barrier use, HIV status of the partner(s), known sexual practices of the partner, and alcohol or drug use prior to the initiation of sexual activity. The SERBAS identifies frequency on a Likert-type scale as "all the time or 9 times out of $10=5$, most of the time or 7 times out of $10=4$, half of the time or 5 times out of $10=3$, sometimes or 3 times out of $10=2$, or never $=1$." The SERBAS was used to assess consistency of male and female condom use.

\section{Barrier methods questionnaire}

This measure was adapted from the University of California at San Francisco Center for AIDS Prevention Studies (UCSF CAPS) Barrier Questionnaire and measures the use and acceptability of various types of sexual barriers (male and female condoms, microbicides). Participants rate current and previous use of and preferences for sexual barriers. Items include: preferences for delivery systems, methods of use, temporal limitations, product characteristics (eg, sticky, dry, pleasurable), and contraceptive characteristics.

\section{Sexual diary}

Participants were asked to recount their sexual activities, indicating for each day of the week whether or not they had intercourse, and if so, the type of sexual barrier method used, if any. This diary used a pictorial representation of the five types of sexual barrier products that were introduced in the intervention.

\section{Statistical analyses}

Analyses were conducted with contraception use as the between-subjects factor and demographic variables and

Table I Demographic data on HIV-positive men and women in Zambia

\begin{tabular}{|c|c|}
\hline Number of participants & $\mathrm{n}=409$ \\
\hline Number of seronegative partners & $n=22$ \\
\hline \multirow[t]{2}{*}{ Gender } & Male $n=201(49 \%)$ \\
\hline & Female $n=208(5 \mathrm{I} \%)$ \\
\hline \multirow[t]{4}{*}{ Age $(y r)$} & Range: 19-69 \\
\hline & (Mean: 37.40; SD: 7.98) \\
\hline & Mean for men: $4 \mathrm{I}$ \\
\hline & Mean for women: 34 \\
\hline \multirow[t]{4}{*}{ Ethnicity/nationality } & Zambian: 403 (98.5\%) \\
\hline & Tanzanian: I (0.2\%) \\
\hline & Malawian: I (0.2\%) \\
\hline & Zimbabwean: 4 (1\%) \\
\hline \multirow[t]{4}{*}{ Employment status } & Work full time: $5 \mathrm{I}$ (12.5\%) \\
\hline & Work part time: 85 (20.8\%) \\
\hline & Not working: I8I (44.3\%) \\
\hline & Volunteering: 92 (22.5\%) \\
\hline \multirow[t]{5}{*}{ Income (per annum) } & Less than $\$ 5000: 332(81.2 \%)$ \\
\hline & $\$ 5000-\$ 10000: 20(4.9 \%)$ \\
\hline & $\$ 10000-\$ 19999: 18$ (4.4\%) \\
\hline & $\$ 20000-\$ 29999: 6(1.5 \%)$ \\
\hline & Greater than $\$ 30000: 33$ (8.1\%) \\
\hline Number of participants on a disability benefit (US only) & - \\
\hline Number of participants that have children & $380(92.9 \%)$ \\
\hline Mean number of children per participant & HIV+ participants: 3 (range $0-13$ ) \\
\hline Number of participants with HIV-positive children & $83(23 \%)$ \\
\hline Number of participants currently pregnant & $19(4.7 \%)$ \\
\hline Number of participants trying to become pregnant & $80(19.6 \%)$ \\
\hline \multirow[t]{3}{*}{ Number of participants planning to have more children } & $|3|(32 \%)$ \\
\hline & HIV+ men: $7 \mathrm{I}$ (35\%) \\
\hline & HIV+ women: 60 (29\%) \\
\hline Number of participants attending religious services regularly & Total sample: 366 (90\%) \\
\hline
\end{tabular}


preference as the within-subjects factors. Correlations are reported as Pearson's $r$ statistics; comparisons are reported as $\chi^{2}$ (all comparisons used an alpha (two-tailed) of 0.05 ). Data were analyzed using the Statistical Package for Social Sciences (SPSS). All analyses pooled ethnicities to examine contraceptive use overall.

\section{Results}

\section{Participant characteristics}

Data from participants providing information for all data categories are summarized by country and serostatus in Tables 1 through 4. Seropositive US $(n=380)$ and Zambian $(n=409)$ participants and seronegative US $(n=64)$ and Zambian $(\mathrm{n}=22)$ participants differed in age (seropositive Zambians were younger, $F=192.63, P<0.001$ ), employment status (higher employment rates in Zambia among both seropositive $\left(\chi^{2}=92.88, P<0.001\right)$ and seronegative $\left(\chi^{2}=11.66, P=0.009\right)$ participants $)$, income (lower incomes in Zambian seropositive participants $\left.\left(\chi^{2}=156.48, P<0.001\right)\right)$, and plans for additional pregnancies. Notably, more seropositive $\left(\chi^{2}=72.59, P<0.001\right)$ Zambians had plans to have more children than did seropositive participants in the US.

Among the US participants, more HIV-negative women than men had plans for children $\left(\chi^{2}=14.26, P=0.001\right)$ though mean ages were similar within both the US and Zambian samples. When the data were separated by gender, US HIV-seropositive male participants were older $(F=11.57$, $P=0.001)$, and HIV-seropositive women had lower incomes $\left(\chi^{2}=15.51, P=0.004\right)$ than those US participants who were seronegative. Among Zambians, when data were separated by gender, seronegative and seropositive participants did not differ in employment status, income, education, or plans to have children.

Table 2 Demographic data on HIV-positive men and women in the US

\begin{tabular}{|c|c|}
\hline Number of participants & $\mathrm{n}=380$ \\
\hline Number of seronegative partners & $\mathrm{n}=64$ \\
\hline \multirow[t]{2}{*}{ Gender } & Male $n=192(51 \%)$ \\
\hline & Female $n=188(49 \%)$ \\
\hline \multirow[t]{4}{*}{ Age $(y r)$} & Range: $22-73$ \\
\hline & (Mean: 45.08; SD: 7.525) \\
\hline & Mean for men: 47 \\
\hline & Mean for women: 43 \\
\hline \multirow[t]{4}{*}{ Ethnicity/nationality } & White non-Hispanic: 42 (I I.I\%) \\
\hline & African-American: 294 (77.4\%) \\
\hline & Haitian/Haitian Bahamian: 6 (I.6\%) \\
\hline & Hispanic: 38 (10\%) \\
\hline \multirow[t]{4}{*}{ Employment status } & Work full time: 30 (7.9\%) \\
\hline & Work part time: 43 ( 1 I.3\%) \\
\hline & Not working: 289 (76.1\%) \\
\hline & Volunteering: I 8 (4.7\%) \\
\hline \multirow[t]{5}{*}{ Income (per annum) } & Less than $\$ 5000$ : $197(51.8 \%)$ \\
\hline & $\$ 5000-\$ 10000: 147$ (38.7\%) \\
\hline & $\$ 10000-\$ 19999: 29(7.6 \%)$ \\
\hline & $\$ 20000-\$ 29999: 3(0.8 \%)$ \\
\hline & Greater than $\$ 30000: 4$ (I.1\%) \\
\hline Number of participants on a disability benefit (US only) & $206(54 \%)$ \\
\hline Number of participants that have children & $290(76.3 \%)$ \\
\hline Mean number of children per participant & HIV+ participants: 3 (range 0-22) \\
\hline Number of participants with HIV-positive children & $14(4 \%)$ \\
\hline Number of participants currently pregnant & $2(0.5 \%)$ \\
\hline Number of participants trying to become pregnant & $14(3.7 \%)$ \\
\hline \multirow[t]{3}{*}{ Number of participants planning to have more children } & $29(7.6 \%)$ \\
\hline & HIV+ men: $18(9 \%)$ \\
\hline & HIV+ women: II (6\%) \\
\hline Number of participants attending religious services regularly & $206(54 \%)$ \\
\hline
\end{tabular}


Table 3 Demographic data on HIV-negative men and women in Zambia

\begin{tabular}{|c|c|}
\hline Number of participants & $\mathrm{n}=22$ \\
\hline Number of seronegative partners & $\mathrm{n}=409$ \\
\hline \multirow[t]{2}{*}{ Gender } & Male $n=14(63.6 \%)$ \\
\hline & Female $n=8(36.4 \%)$ \\
\hline \multirow[t]{4}{*}{ Age $(y r)$} & Range: $25-58$ \\
\hline & (Mean: 39.32; SD: 8.66) \\
\hline & Mean for men: 40 \\
\hline & Mean for women: 39 \\
\hline \multirow[t]{2}{*}{ Ethnicity/nationality } & Zambian: 21 (95.5\%) \\
\hline & Congolese: I (4.5\%) \\
\hline \multirow[t]{4}{*}{ Employment status } & Work full time: 5 (22.7\%) \\
\hline & Work part time: 8 (36.4\%) \\
\hline & Not working: 7 (3I.8\%) \\
\hline & Volunteering: 2 (9.1\%) \\
\hline \multirow[t]{4}{*}{ Income (per annum) } & Less than $\$ 5000$ : I 7 (77.3\%) \\
\hline & $\$ 5000-\$ 10000: 2$ (9.1\%) \\
\hline & $\$ 10000-\$ 19999: 1(4.5 \%)$ \\
\hline & Greater than $\$ 30000: 2(9.1 \%)$ \\
\hline Number of participants on a disability benefit (US only) & - \\
\hline Number of participants that have children & $20(91 \%)$ \\
\hline Mean number of children per participant & 4 (range $0-8$ ) \\
\hline Number of participants with HIV-positive children & $4(20 \%)$ \\
\hline Number of participants currently pregnant & I (4.5\%) \\
\hline Number of participants trying to become pregnant & $4(18.2 \%)$ \\
\hline \multirow[t]{3}{*}{ Number of participants planning to have more children } & $8(36.4 \%)$ \\
\hline & HIV- men: 5 (36\%) \\
\hline & HIV- women: 3 (38\%) \\
\hline Number of participants attending religious services regularly & $19(86 \%)$ \\
\hline
\end{tabular}

\section{Contraceptive planning and use} Zambia

Less than half of seropositive participants $(n=94,46 \%)$ reported using contraception all of the time and 34 participants (17\%) never used any form of contraception in the month prior to study entry (see Tables 5 and 6). Of all seropositive participants, $17(10 \%)$ reported using protection to prevent pregnancy, and $72(43 \%)$ stated that they used protection to prevent STD transmission, while 72 (43\%) stated they used protection for both purposes. However, the majority of seropositive participants stated that they would be very willing $(307,75 \%)$ to use protection to prevent pregnancy.

Of seronegative participants, $6(67 \%)$ reported using contraception all of the time and $1(11 \%)$ never used any form of contraception in the month prior to study entry. Of the seronegative participants, none endorsed using protection to prevent pregnancy, $4(50 \%)$ stated that they used protection to prevent STD transmission, and 4 (50\%) stated that they used protection for both purposes, though all of

these participants had seropositive partners. However, the majority of seronegative participants stated that they would be very willing $(16,73 \%)$ to use protection to prevent pregnancy and $18(82 \%)$ said they would be very willing to use protection to prevent pregnancy and STD transmission.

\section{US}

Similar to the results obtained in the Zambian sample, less than half of seropositive participants $(n=117,48 \%)$ reported that they used contraception all of the time and 58 (23\%) never used any form of contraception in the month prior to study entry (see Tables 7 and 8). Of the seropositive participants, 7 (4\%) stated that they used protection to prevent pregnancy, $112(60 \%)$ reported that they used protection to prevent STD transmission, and 55 (29\%) stated that they used protection for both purposes. The majority of seropositive participants stated that they would be very willing ( 277 , $73 \%$ ) to use protection to prevent pregnancy.

In contrast to Zambian results, $44 \%$ of seronegative participants $(n=19)$ used contraception all of the time and 
Table 4 Demographic data on HIV-negative men and women in the US

\begin{tabular}{|c|c|}
\hline Number of participants & $\mathrm{n}=64$ \\
\hline Number of seronegative partners & $\mathrm{n}=380$ \\
\hline \multirow[t]{2}{*}{ Gender } & Male $n=29(45.3 \%)$ \\
\hline & Female $n=25(54.7 \%)$ \\
\hline \multirow[t]{4}{*}{ Age (yr) } & Range: $20-59$ \\
\hline & (Mean: 42.08; SD: 8.68) \\
\hline & Mean for men: 42 \\
\hline & Mean for women: 42 \\
\hline \multirow[t]{3}{*}{ Ethnicity/nationality } & White non-Hispanic: 12 (18.8\%) \\
\hline & African-American: 37 (57.8\%) \\
\hline & Hispanic: I5 (23.5\%) \\
\hline \multirow[t]{4}{*}{ Employment status } & Work full time: 8 (12.5\%) \\
\hline & Work part time: 7 (10.9\%) \\
\hline & Not working: 46 (71.9\%) \\
\hline & Volunteering: 2 (4.7\%) \\
\hline \multirow[t]{5}{*}{ Income (per annum) } & Less than $\$ 5000: 41$ (64.1\%) \\
\hline & $\$ 5000-\$ 10000: 14$ (21.9\%) \\
\hline & $\$ 10000-\$ 19999: 3(4.7 \%)$ \\
\hline & $\$ 20000-\$ 29999: 3(4.7 \%)$ \\
\hline & Greater than $\$ 30000: 3$ (4.7\%) \\
\hline Number of participants on a disability benefit (US only) & $20(31 \%)$ \\
\hline Number of participants that have children & $5 \mathrm{I}(80 \%)$ \\
\hline Mean number of children per participant & 3 (range $1-13$ ) \\
\hline Number of participants with HIV-positive children & 0 \\
\hline Number of participants currently pregnant & $2(3.1 \%)$ \\
\hline Number of participants trying to become pregnant & $5(7.8 \%)$ \\
\hline \multirow[t]{2}{*}{ Number of participants planning to have more children } & I3 (20.3\%), HIV- men: 4 (I4\%) \\
\hline & HIV- women: 9 (26\%) \\
\hline Number of participants attending religious services regularly & $32(50 \%)$ \\
\hline
\end{tabular}

Number of participants attending religious services regularly

$8(19 \%)$ never used any form of contraception in the month prior to study entry. Similar to Zambia, of the seronegative participants, none endorsed using protection to prevent pregnancy, but more US participants, 22 (63\%), stated that they used protection to prevent STD transmission and 11 (31\%) stated that they used protection for both purposes. However, the majority of US seronegative participants stated that they would be very willing $(42,66 \%)$ to use protection to prevent pregnancy and $52(81 \%)$ said they would be very willing to use protection to prevent pregnancy and STD transmission.

\section{Age-related analyses}

We compared plans for children by serostatus between the two samples, separating both samples by gender and age. Based on the anticipated fertility of the female samples, we divided those samples at 45 years of age and compared reproductive desires by age group and gender.

\section{Zambia}

Obtained percentages of male participants endorsing plans to have children differed between serostatus categories (positive, negative) though the majority of neither positive nor negative men (all of whom were in a relationship with a seropositive partner) planned to have more children. However, greater numbers of both younger $\left(\chi^{2}=49.96, P<0.001\right)$ and older $\left(\chi^{2}=7.36, P<0.001\right)$ seropositive men planned to have more children compared to seronegative men. Among younger female participants, more seropositive women planned to have additional children $\left(\chi^{2}=49.59, P<0.001\right)$. In contrast, older seropositive women expressed no desire to have more children $\left(\chi^{2}=6.4, P=0.011\right)$.

\section{US}

Obtained percentages of male participants endorsing plans to have children differed between serostatus categories (positive, negative) though the majority of neither positive nor negative men (all of whom were in a relationship with a seropositive partner) planned to have more children. However, greater numbers of younger seropositive men than seronegative men planned to have more children $\left(\chi^{2}=7.12, P<0.001\right)$. There were no differences in the desire to have children between serostatus groups among 
Table 5 Contraceptive use and planning: HIV-positive men and women in Zambia

\section{Number of participants \\ Number of seronegative partners \\ How willing would you be to use a product that could protect against HIV reinfection or transmission?}

How willing would you be to use a product that could prevent pregnancy?

How willing would you be to use a product that could prevent pregnancy and protect against HIV and other sexually transmitted diseases?

How willing would you be to use a product that could allow you to get pregnant but still protect against infection from other sexually transmitted diseases?

In the past month, during times when you had vaginal sex, how often did you or he use any form of protection?

Why did you use this/these form(s) of protection?

How often did you use:

Male condom:

Female condom: $\mathrm{n}=409$

$\mathrm{n}=22$

Not at all willing to use: 73 (I7.8\%)

Slightly willing to use: $12(2.9 \%)$

Moderately willing to use: 8 (2\%)

Very willing to use: $316(77.3 \%)$

Not at all willing to use: 58 (14.2\%)

Slightly willing to use: 16 (3.9\%)

Moderately willing to use: 28 (6.8\%)

Very willing to use: 307 (75.1\%)

Not at all willing to use: 53 (13\%)

Slightly willing to use: $12(2.9 \%)$

Moderately willing to use: I I $(2.7 \%)$

Very willing to use: 333 (8I.4\%)

Not at all willing to use: 145 (35.5\%)

Slightly willing to use: 30 (7.3\%)

Moderately willing to use: $26(6.4 \%)$

Very willing to use: 208 (50.9\%)

Never in the past month: 34 (16.7\%)

Sometimes: 35 (17.2\%)

Half of the time: 8 (3.9\%)

Most of the time: 32 (15.8\%)

All of the time: $94(46.3 \%)$

To protect against sexually transmitted diseases: 72 (42.6\%)

To prevent pregnancy: 17 (10.1\%)

Both: 72 (42.6\%), Other: 8 (4.7\%)

Never in the past month: 10 (5.9\%)

Sometimes: 33 (19.5\%)

Half of the time: I $(0.6 \%)$

Most of the time: 33 (19.5\%)

All of the time: 92 (54.4\%)

Never in the past month: I I 8 (69.8\%)

Sometimes: 23 (13.6\%)

Half of the time: I $(0.6 \%)$

Most of the time: $10(5.9 \%)$

All of the time: 17 (I0.I\%) older men $\left(\chi^{2}=1.80, P<0.001\right)$. Among younger female participants of both serostatus groups, most women did not plan to have more children. However, there was no difference between serostatus groups $\left(\chi^{2}=0.47, P=0.491\right)$. No women in the older age groups endorsed plans for having more children.

\section{Discussion}

This study explored attitudes and practices regarding contraception in HIV-seropositive and -serodiscordant couples the US and Zambia. Results from both sites suggest that, while most couples reported no plan to have more children and expressed a willingness to use protection to prevent pregnancy, the majority were not engaging in condom use consistently and many were not using any form of contraception at all. Similarly, among the Zambian and US seropositive younger age group, more men expressed a desire to have children than women of either serostatus group. Finally, more Zambians endorsed plans to have more children, regardless of serostatus.

Though the two country populations differed with regard to several demographic factors, frequency of condom use was remarkably similar. The majority of seronegative participants did not endorse consistent condom use, and less than half used some sort of protection consistently. In contrast, more than half of the seronegative 
Table 6 Contraceptive use and planning: HIV-positive men and women in the US

\section{Number of participants \\ Number of seronegative partners \\ How willing would you be to use a product that could protect against HIV reinfection or transmission? \\ How willing would you be to use a product that could prevent pregnancy?}

How willing would you be to use a product that could prevent pregnancy and protect against HIV and other sexually transmitted diseases?

How willing would you be to use a product that could allow you to get pregnant but still protect against infection from other sexually transmitted diseases?

In the past month, during times when you had vaginal sex, how often did you or he use any form of protection?

Why did you use this/these form(s) of protection?

How often did you use:

Male condom:

Female condom:

$$
\begin{aligned}
& n=380 \\
& n=64
\end{aligned}
$$

Not at all willing to use: 2 I $(5.5 \%)$

Slightly willing to use: I 2 (3.2\%)

Moderately willing to use: $18(4.7 \%)$

Very willing to use: 329 (86.6\%)

Not at all willing to use: 63 (16.6\%)

Slightly willing to use: 18 (4.7\%)

Moderately willing to use: 22 (5.8\%)

Very willing to use: 277 (72.9\%)

Not at all willing to use: $37(9.7 \%)$

Slightly willing to use: 12 (3.2\%)

Moderately willing to use: 17 (4.5\%)

Very willing to use: 3 I 4 (82.6\%)

Not at all willing to use: 125 (32.9\%)

Slightly willing to use: $20(5.3 \%)$

Moderately willing to use: 31 (8.2\%)

Very willing to use: 204 (53.7\%)

Never in the past month: 56 (23\%)

Sometimes: 3 I (12.7\%)

Half of the time: 15 (6.1\%)

Most of the time: 25 (10.2\%)

All of the time: II (48\%)

To protect against sexually transmitted diseases: I I 2 (59.6\%)

To prevent pregnancy: 7 (3.7\%)

Both: 55 (29.3\%), Other: 14 (7.4\%)

Never in the past month: 4 (2.1\%)

Sometimes: 2 I (I I.2\%)

Half of the time: $13(6.9 \%)$

Most of the time: 29 (15.4\%)

All of the time: I 2 I (64.4\%)

Never in the past month: 136 (72.3\%)

Sometimes: I 6 (8.5\%)

Half of the time: $10(5.3 \%)$

Most of the time: 7 (3.7\%)

All of the time: 19 (10.1\%) participants used protection, but primarily for the purpose of prevention of transmission rather than prevention of pregnancy. Study outcomes suggest that condom use to reduce HIV transmission within couples is limited among seroconcordant couples, which may have been due to an assumed 'invulnerability' to infection. More importantly, the lack of differences observed among younger women of both countries and in both positive and negative serostatus groups suggests that reproductive desires held by women may not change following HIV infection. This suggests an important area for intervention to ensure prevention of MTCT, especially in the developing world where adherence to medications associated with prevention of MTCT has been variable. Similarly, in both locations, lifestyle interventions during pregnancy may be merited to address the special needs of women on HAART and of their children, to ensure optimal adherence and follow up during pregnancy and post-partum.

A desire for more children was expressed by more seropositive Zambian men than those Zambians, of either gender, who were seronegative. Thus, seronegative Zambian women, who may not desire children, may not be able to negotiate condom use to protect themselves from HIV infection owing to their partners' wishes for children. As men are the primary decision-makers regarding male condom use, women's attitudes or plans regarding childbearing may 
Table 7 Contraceptive use and planning: HIV-negative men and women in Zambia

Number of participants
Number of seronegative partners
How willing would you be to use a product that could protect
against HIV reinfection or transmission?
How willing would you be to use a product that could prevent
pregnancy?
How willing would you be to use a product that could prevent
pregnancy and protect against HIV and other sexually transmitted
diseases?
How willing would you be to use a product that could allow you to
get pregnant but still protect against infection from other sexually
transmitted diseases?
In the past month, during times when you had vaginal sex, how often
did you or he use any form of protection?

Why did you use this/these form(s) of protection?

How often did you use:

Male condom:

Female condom: $n=22$
$n=409$

Not at all willing to use: $2(9.1 \%)$

Slightly willing to use: I (4.5\%)

Moderately willing to use:-Very willing to use: 19 (86.4\%)

Not at all willing to use:4 (18.2\%)

Slightly willing to use: I (4.5\%)

Moderately willing to use: I (4.5\%), Very willing to use: I6 (72.7\%)

Not at all willing to use: $2(9.1 \%)$

Slightly willing to use:- Moderately willing to use: 2 (9.1\%)

Very willing to use: 18 (8I.8\%)

Not at all willing to use: 4 (18.2\%)

Slightly willing to use:- Moderately willing to use:-Very willing to use: $18(81.8 \%)$

Never in the past month: I (II.I\%)

Sometimes: I (I I.I\%)

Half of the time: I (II.I\%)

Most of the time:-All of the time: $6(66.7 \%)$

To protect against sexually transmitted diseases: 4 (50\%)

To prevent pregnancy: - Both: 4 (50\%), Other:- thus be eclipsed by their male partners' desires. Reductions in the provision of female condoms in Zambia may further reduce women's abilities to protect themselves and prevent pregnancy. Desires for more children may also be influenced by a lack of knowledge regarding MTCT and the potential for infection of the neonate during pregnancy. Future studies should examine the association between knowledge and behavior and should include men in the MTCT process, providing education to both members of the couple regarding reproductive plans and strategies for safer sex and safer pregnancy.

This study may not be widely generalizable and it utilized a highly specific cohort in the US; the majority of US participants had extremely low incomes. Study limitations include a lack of dyadic analyses that might have provided additional information regarding the influence of couple members' attitudes on each other's attitudes and behaviors. Future studies should utilize more sophisticated dyadic analytic techniques addressing the influence of partner preferences as well as behavior on behavioral outcomes.
Never in the past month:- Sometimes: I (I2.5\%)

Half of the time:- Most of the time: I (I2.5\%)

All of the time: 6 (75\%)

Never in the past month: 5 (62.5\%)

Sometimes:- Half of the time:- Most of the time: I (I2.5\%)

All of the time: $2(25 \%)$
This study highlights the similarity of reproductive plans among seronegative persons and those living with HIV in the US and Zambia. Clearly, efforts to reduce transmission that do not include attention to reproductive planning of both men and women may be of limited efficacy. Education and counseling on the vertical and horizontal transmission of HIV among both seropositive and serodiscordant couples should be an element of family planning efforts. Conversely, family planning should be a critical element of HIV counseling and testing strategies to realistically respond to the desires of both members of the couple.

\section{Acknowledgments}

This study was made possible by a grant from the National Institutes of Health (NIH) no. R01MH63630. We would like to acknowledge the contribution of study team members Jennifer Casani and Szonja Vamos, as well as recruitment referrals by agencies in both the US and Zambia. Most importantly, we would like to acknowledge the willingness of couples to participate, couples without whom this study would not have been possible. 
Table 8 Contraceptive use and planning: HIV-negative men and women in the US

\section{Number of participants \\ Number of seronegative partners}

How willing would you be to use a product that could protect against HIV reinfection or transmission?

How willing would you be to use a product that could prevent pregnancy?

How willing would you be to use a product that could prevent pregnancy and protect against HIV and other sexually transmitted diseases?

How willing would you be to use a product that could allow you to get pregnant but still protect against infection from other sexually transmitted diseases?

In the past month, during times when you had vaginal sex, how often did you or he use any form of protection?

Why did you use this/these form(s) of protection?

How often did you use:

Male condom:

Female condom:

$$
\begin{aligned}
& n=64 \\
& n=380
\end{aligned}
$$

Not at all willing to use: $4(6.3 \%)$

Slightly willing to use: 2 (3.1\%)

Moderately willing to use: $4(6.3 \%)$

Very willing to use: 54 (84.4\%)

Not at all willing to use: $13(20.3 \%)$

Slightly willing to use: 5 (7.8\%) Moderately willing to use: 4 (6.3\%)

Very willing to use: $42(65.6 \%)$

Not at all willing to use: 7 (I0.9\%)

Slightly willing to use: I ( $1.6 \%)$ Moderately willing to use: 4 (6.3\%)

Very willing to use: 52 (81.3\%)

Not at all willing to use: 2 I (32.8\%)

Slightly willing to use: 4 (6.3\%) Moderately willing to use: 3 (4.7\%)

Very willing to use: 36 (56.3\%)

Never in the past month: 8 (18.6\%)

Sometimes: 6 (14\%)

Half of the time: $2(4.7 \%)$

Most of the time: 8 (18.6\%)

All of the time: 19 (44.2\%)

To protect against sexually transmitted diseases: 22 (62.9\%)

To prevent pregnancy:- Both: II (3I.4\%)

Other: 2 (5.7\%)

Never in the past month: $3(8.6 \%)$

Sometimes: 5 (14.3\%)

Half of the time:- Most of the time: 7 (20\%)

All of the time: 20 (57.1\%)

Never in the past month: 30 (85.7\%)

Sometimes: 4 (II.4\%)

Half of the time: - Most of the time:-All of the time: I (2.9\%)

\section{Disclosures}

The authors report no conflicts of interest in this work.

\section{References}

1. United Nations Department of Economic and Social Affairs Population Division. World Contraceptive Use 2007. New York: Department of Economic and Social Affairs Population Division; 2007. Available from http://www.un.org/esa/population/publications/contraceptive2007/ contraceptive2007.htm. Accessed December 15, 2009.

2. Jacobstein R, Bakamjian L, Pile JM, Wickstrom J. Fragile, threatened, and still urgently needed: family planning programs in sub-Saharan Africa. Studies Fam Plann. 2009;40(2):147-154.

3. World Health Organization. Contraceptive prevalence rate (percentage); Available from http://www.who.int/whosis/indicators/compendium/2008/ 3pcf/en/print.html. Accessed January 11, 2010.

4. Ministry of Health/Central Board of Health. HIV/AIDS in Zambia. September. Lusaka, Zambia: Republic of Zambia; 2005.

5. Ministry of Health. Office of the Director of Mental Health: Annual Report 2008. Wellington, NZ: Ministry of Health; 2009.

6. Central Statistical Office. Zambia Demographic and Health Survey. Lusaka, Zambia: Central Statistical Office, Zambia; 2002.

7. Carovano K. More than mothers and whores: Re-defining the AIDS prevention needs of women. Int J Health Serv. 1991;21:131-142.
8. Richter DL, Sowell RL, Pluto DM. Factors affecting reproductive decisions of African-American women living with HIV. Women Health. 2002;36(1):81-96.

9. Cooper D, Chipeta J, Aberle-Grasse J. Assessment trends in biological and behavioral surveillance data: Is there any evidence of declining HIV prevalence or incidence in Malawi? Sex Transmit Infect. 2006;82 (Suppl 1):i9-i13.

10. Anand A, Shiraishi RW, Bunnell RE, et al. Knowledge of HIV status, sexual risk behaviors and contraceptive need among people living with HIV in Kenya and Malawi. AIDS. 2009;23(12):1565-1573.

11. Hubacher D, Mavranezouli I, McGinn E. Unintended pregnancy in sub-Saharan Africa: magnitude of the problem and potential role of contraceptive implants to alleviate it. Contraception. 2008;78:73-78.

12. World Health Organization, UNICEF, UNFPA, The World Bank. Maternal mortality in 2005: estimates developed by WHO, UNICEF, UNFPA, and the World Bank. Geneva, Switzerland: World Health Organization; 2007.

13. USAID. World Population Data Sheet. Population Reference Bureau, 2009; Available from http://www.prb.org/pdf09/09wpds_eng.pdf. Accessed December 15, 2009.

14. Grabbe K, Stephenson R, Vwalika B, et al. Knowledge, use, and concerns about contraceptive methods among sero-discordant couples in Rwanda and Zambia. J Womens Health. 2009;18(9):1449-1456.

15. Zorilla C. Navigating Into the New Millennium Through Collaboration. The 1999 National Conference on Women and HIV/AIDS, 1999:9-12 October, Los Angeles. CA. 
16. Centers of Disease Control. HIV/AIDS Surveillance Report, 2006. vol 18. Atlanta, GA: US Department of Health and Human Services; 2008.

17. Davis SF, Byers RH Jr, Lindegren ML, Caldwell MB, Karon JM, Gwinn M. Prevalence and incidence of vertically acquired HIV infection in the United States. JAMA. 1995;274(12):952-955.

18. Sharma A, Feldman JG, Golub ET, et al Live birth patterns among Human immunodeficiency virus-infected women before and after the availability of highly active antiretroviral therapy. Am JObstet Gynecol. 2007;196(6):541.e1-e6.

19. Nattabi B, Li J, Thompson SC, Orach CG, Earnest J. A systematic review of factors influencing fertility desires and intentions among people living with HIV/AIDS: implications for policy and service delivery. AIDS Behav. 2009;13(5):949-968.

20. Craft SM, Delaney RO, Bautista DT, Serovich JM. Pregnancy decisions among women with HIV. AIDS Behav. 2007;11(6):927-935.

21. Martinelli P, Agangi A, Sansone M, et al. Epidemiological and clinical features of pregnant women with HIV. HIV Clin Trials. 2008;9(1):36-42.

22. Bedimo AL, Bessinger R, Kissinger P. Reproductive choices among HIV-positive women. Soc Sci Med. 1998;46(2):171-179.

23. Pivnick A. Loss and regeneration: influences on the reproductive decisions of HIV positive, drug-using women. Med Anthropol. 1994;16(1):39-62.

24. Selwyn PA, Carter RJ, Schoenbaum EE, Robertson VJ, Klein RS, Rogers MF. Knowledge of HIV antibody status and decisions to continue or terminate pregnancy among intravenous drug users. JAMA. 1980;261(24):3567-3571.
25. Sowell RL, Misener TR. Decision to have a baby by HIV-infected women. West J Nurs Res. 1997;19(1):56-70.

26. Murphy DA, Mann T, O'Keefe Z, Rotheram-Borus MJ. Number of pregnancies, outcome expectancies and social norms among HIV-infected young women. Health Psychol. 1998;17(5):70-75.

27. Kline A, Strickler J, Kempf J. Factors associated with pregnancy and pregnancy resolution in HIV seropositive women. Soc Sci Med. 1995;40(11):1539-1547.

28. Wesley Y. Desire for children among black women with and without HIV infection. J Nurs Scholarsh. 2003;35(1):37-43.

29. Wegbreit J, Bertozzi S, DeMaria LM, Padian NS. Effectiveness of HIV prevention strategies in resource-poor countries: tailoring the intervention to the context. AIDS. 2006;20(9):1217-1235.

30. Stuart G. Fourteen million women with limited options: HIV/AIDS and highly effective reversible contraception in sub-Saharan Africa. Contraception. 2009;80:412-416.

31. Jones R. Survey data collection using audio computer assisted selfinterview. West J Nurs Res. 2003;25(3):349-358.

32. Meyer-Bahlberg HFL, Ehrhardt AA, Exner TM, Gruen RS. Sexual Risk Behavior Assessment Schedule: Adult (SERBAS-A-DF-4) Manual. Philadelphia, PA: Springer; 1990.
Open Access Journal of Contraception

\section{Publish your work in this journal}

Open Access Journal of Contraception is an international, peerreviewed, open access, online journal, publishing original research, reports, reviews and commentaries on all areas of contraception. In addition to clinical research, demographics and health-related aspects, the journal welcomes new findings in animal and preclinical studies

\section{Dovepress}

relating to understanding the biological mechanisms and practical development of new contraceptive agents. The manuscript management system is completely online and includes a very quick and fair peer-review system. Visit http://www.dovepress.com/testimonials.php to read real quotes from published authors. 